\title{
Correlation of Helicobacter pylori virulence genotypes vacA and cagA with histological parameters of gastritis and patient's age
}

\author{
Alex Soltermann ${ }^{1}$, Stephan Koetzer ${ }^{2}$, Franz Eigenmann ${ }^{3}$ and Paul Komminoth ${ }^{4}$ \\ ${ }^{1}$ Department of Pathology, Institute of Surgical Pathology, University Hospital Zürich, Zürich, Switzerland; \\ ${ }^{2}$ Institute of Mathematical Statistics and Actuarial Science, University of Bern, Bern, Switzerland; \\ ${ }^{3}$ Department of Internal Medicine, Division of Gastroenterology, Kantonsspital Baden, Baden, Switzerland \\ and ${ }^{4}$ Institute of Pathology, Triemli Hospital Zürich, Zürich, Switzerland
}

\begin{abstract}
The histological parameters of Helicobacter pylori $(H$. pylori) gastritis are dependent on the virulence factor profile of the microbe, which includes the cytotoxins vacA (vacuolating cytotoxin A) and cagA (cytotoxinassociated gene A) as well as the duration of infection. The virulence factor genotypes vacA and cagA were assessed by the line probe reverse hybridization assay INNO-LiPA and correlated with the histological parameters of $\boldsymbol{H}$. pylori infection, in particular intestinal metaplasia (IM) as well as with the patient's age. A total of 120 patients were analyzed; 47 patients with IM in the antrum and 73 control patients without this alteration. The vacA s1 cagA + genotype (high virulence) correlated with the presence of antral IM, a more intense acute inflammation in both antrum and corpus and the formation of ulcer. The vacA m1 genotype (high virulence) correlated with a more intense acute inflammation in only the corpus as well as more prominent Russell bodies in the antrum. H. pylori strains with the vacA s2 m2 cagA- genotype (low virulence) were rarely found in these conditions (all $\boldsymbol{P}<\mathbf{0 . 0 5}$ ). No correlation with the virulence status was found for the type and extent of IM, the intensity of chronic inflammation, the formation of lymphoid follicles and the microbial density. Furthermore, patients with IM were 7 years older than their counterparts without $(P<0.05)$. Finally, there was a trend for more virulent vacA s1 $\mathrm{m} 1 \mathrm{cagA}+$ strains to be found in younger individuals $(P>0.05)$. The virulence genotype of the microbe is an important determinant for the severity of the gastritis and the formation of antral IM. Age is an additional factor for the development of IM.

Modern Pathology (2007) 20, 878-883; doi:10.1038/modpathol.3800832; published online 1 June 2007
\end{abstract}

Keywords: Helicobacter, virulence; gastritis; histology; resistance

The Gram-negative bacteria Helicobacter pylori colonize the human stomach. ${ }^{1}$ Prolonged infection is associated with several diseases like chronic gastritis, peptic ulcer disease and stomach carcinoma or lymphoma. This association depends on bacterial, host and environmental factors. Among the bacterial factors, several virulence proteins determine the severity of inflammation and the formation of intestinal metaplasia (IM). ${ }^{2-5}$

The most studied virulence proteins are vacA and cagA, which are injected into the gastric epithelial cell through a multimeric protein complex. ${ }^{6}$ This

Correspondence: Dr A Soltermann, MD, Institute of Surgical Pathology, University Hospital Zürich, Schmelzbergstrasse 12, CH-8091 Zürich, Switzerland.

E-mail: alex.soltermann@usz.ch

Received 13 November 2006; revised 10 April 2007; accepted 07 May 2007; published online 1 June 2007 protein complex is elaborated from the PAI (pathogenicity-island), a $40 \mathrm{~kb}$ DNA segment. CagA makes part of the PAI and targets particularly the phosphorylation cascade and the tight junctions. ${ }^{7-9} \mathrm{H}$. pylori are either cagA-positive or -negative. VacA, present in all $H$. pylori, is located outside the PAI and forms an oligomeric pore with channel activity. ${ }^{10,11}$ VacA has two variable parts: The s (signal peptide) region exists as allele $\mathrm{s} 1$ or $\mathrm{s} 2$. The $\mathrm{m}$ (middle) region occurs as $\mathrm{m} 1$ or $\mathrm{m} 2$ allelic type. The allele combination s1 $\mathrm{m} 1$ confers high, s1 m2 intermediate and $\mathrm{s} 2 \mathrm{~m} 2$ low toxin activity. Most vacA s1 strains are cagA-positive, thus the two markers are closely related. ${ }^{12}$

$H$. pylori infection is normally acquired in early childhood through intra-familial transmission followed by an immune response and establishment of a mixed acute and chronic inflammation. The elaborated virulence factors are able to act for 
decades on the mucosa, thus the histological parameters of gastritis are determined by the duration of the infection and the patient's age, respectively.

In our study, we aimed for correlation of the virulence factor (cagA and vacA genotypes (1) with the histological parameters of the $H$. pylori gastritis, particularly IM, and (2) with the patient's age.

\section{Materials and methods}

\section{Study Design}

One hundred and twenty-seven sequential patients with $H$. pylori-positive antrum biopsy, diagnosed by the first author, were enrolled in an 18-month time period. In 47 of them, the histological parameter IM was present in the antrum. In the other 73, no IM was found (control group). Patients presenting single goblet cells in their antrum mucosa were not included in the study. The positive diagnosis of $H$. pylori infection was made on the Giemsa-C stain. In cases of uncertainty, immunohistochemistry with a rabbit polyclonal antibody (DAKO-Cytomation) was performed. Only unequivocal positive cases were included. The status of the virulence genotype was not known at the time point of enrolment. Seven patients were removed after virulence genotype assessment because of incomplete vacA genotype (three patients) or no PCR product (four patients).

\section{Histology}

Two antrum (one bloc) and two corpus biopsies (one bloc) were fixed in buffered formaldehyde and processed by paraffin-embedding and $\mathrm{H} \& \mathrm{E}$ staining. Additionally, Giemsa-C and AB-PAS (alcian-blue/ periodic acid schiff) stained sections were produced (all $4 \mu \mathrm{m}$ ). Corpus biopsies were available for only 80 patients. Two to four sections were cut from each bloc and mounted on one glass slide for each of the three stains; thus a total of 12-24 sections of either antrum or corpus mucosa was analyzed according to the semiquantitative ordinal scale of the updated Sydney classification. ${ }^{13}$ The degree of acute and chronic inflammation as well as the microbial density were scored 0-3. Further, we implemented a similar semiquantitative score $0-3$ for the size/ number of lymphoid aggregates and for the size/ number of Russell bodies. Russell bodies were counted on 20 high power fields in the outer half of the mucosa on the AB-PAS-stained sections. The IM was typed complete (type 1), incomplete (type 2) and mixed complete/incomplete. For the category complete IM, we required that all visible areas on all sections consisted only of metaplastic mucosa with all of the following features: complete brush border, absorptive cells, goblet cells, Paneth and/or neuroendocrine cells. Finally, the extent of IM was scored 1-3.

\section{DNA Extraction}

Fifty micrometers $(5 \times 10 \mu \mathrm{m}$ sections $)$ were cut on a microtome from the paraffin bloc with the two antrum biopsies and dewaxed in a microtube with $500 \mu \mathrm{l}$ of xylene at $50^{\circ} \mathrm{C}$ for $15 \mathrm{~min}$ followed by washings with 100 and $70 \%$ ethanol. The microtome was cleaned and the blade was changed after each bloc. The pellets were digested with proteinase $\mathrm{K}(1.75 \mathrm{mg} / \mathrm{ml})$ in $100 \mu \mathrm{l}$ digestion buffer $(100 \mathrm{mM}$ Tris, pH 8.0, 5 mM EDTA, 0.5\% NP-40, 0.5\% Tween20) at $54^{\circ} \mathrm{C}$ for $24 \mathrm{~h}$, followed by enzyme inactivation at $94^{\circ} \mathrm{C}$ for $10 \mathrm{~min}$. An aliquot of the extraction digest was used for PCR.

\section{Polymerase Chain Reaction}

PCR was performed on a 6700 cycler (Applera Biosciences) with the primer mix from the line probe reverse hybridization $H$. pylori virulence kit (INNO-LiPA, Innogenetics, Netherlands ${ }^{14}$ ). A standard PCR of $50 \mu \mathrm{l}$ and 45 cycles, using $1 \mu \mathrm{l}$ of digestion extract, was run with $30 \mathrm{~s}$ denaturation at $94^{\circ} \mathrm{C}, 30 \mathrm{~s}$ annealing at $50^{\circ} \mathrm{C}$ and $30 \mathrm{~s}$ of extension at $72^{\circ} \mathrm{C}$. Formation of PCR product was checked on agarose gel electrophoresis. To test for DNA adequacy, we used a second PCR with primer pair CRF-4/CCR-1, spanning a $135 \mathrm{bp}$ segment in the 23s rRNA of the microbe. ${ }^{15}$ Ileum mucosa, a vas deferens specimen and blood DNA from healthy individuals served as negative controls. As positive controls, we used cell culture extracts from H. pylori strains V15-37469 (vacA s2 m2 cagA-), V15-37400 (vacA s1a/b m1 cagA +) and V15-4434 (vacA s1b m1 cagA + ), kindly provided by $\mathrm{Dr} R$ Zbinden (Institute of Microbiology, University of Zürich).

\section{Line Probe Reverse Hybridization}

The line probe kit assay was performed according to the manufacturer's recommendations in a closed water bath by hybridization of the PCR product at $50^{\circ} \mathrm{C}$ for $1 \mathrm{~h}$, followed by a stringent wash at $50^{\circ} \mathrm{C}$ for $30 \mathrm{~min}$ and visualization reaction.

\section{Statistical Analysis}

Data were analyzed using the statistical software SAS. To detect correlations between different parameters of interest, we have applied known statistical testing procedures, ${ }^{16,17}$ which are indicated in the corresponding tables of this paper. A binary logistic regression using IM as the binary dependent, and age, sex and vacA s allele $\times$ cagA as the independent variables was established to test for influence on IM. 


\section{Results}

\section{Genotype and IM}

Table 1 gives an overview of the frequency distribution of the vacA $s$ and $m$ alleles and the cagA status. The vacA alleles $\mathrm{s} 1$ and $\mathrm{m} 2$ as well as cagA + were predominant. Mixed vacA s1 s2 genotypes were found in eight patients (6\%). The subtypes vacA s1a and m2a were highly predominant, s1c and $\mathrm{m} 2 \mathrm{~b}$ found each in only one patient. Concerning genotype combinations, vacA s1 m1 cagA + and vacA s1 $\mathrm{m} 2$ cagA + were most frequent, followed by vacA s2 $\mathrm{m} 2$ cagA-. The vacA s2 m1 genotype was not observed (Table 2). Significant correlations in the presence of antral IM were found for vacA s1 and cagA + (exact $P<0.05$, Table 3 ). Regarding the types of IM, there was a trend for the more virulent genotype vacA $\mathrm{s} 1 \mathrm{~m} 1 \mathrm{cagA}+$ to be associated with incomplete IM, although without statistical significance (Table 4). When scoring the extent of IM semiquantitatively (1-3), no correlation with the virulence genotype was observed.

\section{Genotype and Gastritis Parameters}

The virulence genotypes of the 120 patients were further correlated with the parameters acute and

Table 1 Frequency distribution of the vacA allele variants s and $\mathrm{m}$ and the cagA status for the total of study patients analyzed

\begin{tabular}{lrr}
\hline Genotype & \multicolumn{2}{c}{ Total } \\
\cline { 2 - 3 } & $\mathrm{n}$ & $\%$ \\
\hline vacA s-region & & \\
s1 & 86 & 72 \\
s2 & 26 & 62 \\
s1 and s2 & 8 & \\
vacA m-region & & 33 \\
m1 & 40 & 67 \\
m2 & 80 & 72 \\
cagA & & 28 \\
Positive & 86 & 100 \\
Negative & 34 & \\
Total & 120 & \\
\hline
\end{tabular}

Table 2 Frequency distribution of the different genotype combinations for the total of patients analyzed

\begin{tabular}{lcc}
\hline Genotype & Frequency & Percentage \\
\hline vacA s1 m1 cagA+ & 40 & 33.3 \\
vacA s1 m2 cagA- & 6 & 5.0 \\
vacA s1 m2 cagA+ & 40 & 33.3 \\
vacA s2 m2 cagA- & 26 & 21.7 \\
vacA s1+2 m2 cagA- & 2 & 1.7 \\
vacA s1+2 m2 cagA+ & 6 & 5.0 \\
Total & 120 & 100.0 \\
\hline
\end{tabular}

chronic inflammation as well as microbe density by comparing score $0 / 1$ vs $2 / 3$ (Table 5 ). The vacA s1 allele and cagA + correlated with a higher grade $2-3$ acute inflammation of both antrum and corpus mucosa as well as ulcer formation $(P<0.05)$. The vacA $m 1$ allele was only in the corpus significant for higher grade acute inflammation. The parameter chronic inflammation of the Sydney classification refers to the diffuse stromal lympho-plasmocytic infiltrate. We implemented additionally a semiquantitative score $0-3$ for lymphoid follicles and for Russell bodies. No correlation of the virulence status was observed with the intensity of chronic inflammation and the formation of lymphoid follicles, whereas more prominent antral Russell bodies correlated with the vacA $\mathrm{m} 1$ allele. Finally, no correlation was observed with the microbe density.

\section{IM and Age}

We hypothesized that the formation of IM and/or the intensity of inflammation could rather be a function of age than of the virulence genotype and thus correlated these parameters with the patient's age. The mean age of the total study population was 50.5 years. The patients with IM were 7 years older than those without IM $(P<0.05)$. The mean age of the

Table 3 Correlation of virulence genotypes vacA and cagA with the presence of IM in the antrum ( $P$-values of Fisher's exact test)

\begin{tabular}{|c|c|c|c|c|c|}
\hline & $\operatorname{vac} A s 1$ & $\operatorname{vac} A s 2$ & $\operatorname{vac} A s 1+2$ & Total & P-value (exact) \\
\hline $\mathrm{IM}+$ & 37 & 5 & 5 & 47 & 0.0355 \\
\hline \multirow[t]{2}{*}{$\mathrm{IM}-$} & 49 & 21 & 3 & 73 & \\
\hline & $\operatorname{vac} A \mathrm{~m} 1$ & $\operatorname{vac} A \mathrm{~m} 2$ & & Total & $\mathrm{P}$-value (exact) \\
\hline \multirow{3}{*}{$\begin{array}{l}\mathrm{IM}+ \\
\mathrm{IM}-\end{array}$} & 19 & 28 & & 47 & 0.2345 \\
\hline & 21 & 52 & & 73 & \\
\hline & $\operatorname{cag} A+$ & $\operatorname{cag} A-$ & & Total & P-value (exact) \\
\hline $\mathrm{IM}+$ & 41 & 6 & & 47 & 0.0033 \\
\hline IM- & 45 & 28 & & 73 & \\
\hline
\end{tabular}

Table 4 Correlation of the virulence genotypes with the type of IM ( $P$-values of Fisher's exact test)

\begin{tabular}{lrrrrr}
\hline $\begin{array}{l}\text { Type of } \\
\text { IM }\end{array}$ & Complete & Incomplete & Mixed & Total & $\begin{array}{c}\text { P-value } \\
\text { (exact) }\end{array}$ \\
\hline vacA s1 & 12 & 19 & 6 & 37 & 0.8433 \\
vacA s2 & 3 & 2 & 0 & 5 & \\
vacA s1+2 & 2 & 3 & 0 & 5 & \\
vacA m1 & 4 & 11 & 4 & 19 & 0.1515 \\
vacA m2 & 13 & 13 & 2 & 28 & \\
cagA+ & 14 & 21 & 6 & 41 & 0.7116 \\
cagA- & 3 & 3 & 0 & 6 & \\
Total & 17 & 24 & 6 & 47 & \\
\end{tabular}


Table 5 Correlation of the virulence genotypes with histological parameters of $H$. pylori gastritis $(P$-values of Fisher's exact test, ordinal score $0 / 1$ vs $2 / 3$ ), bold italic: $P<0.05$

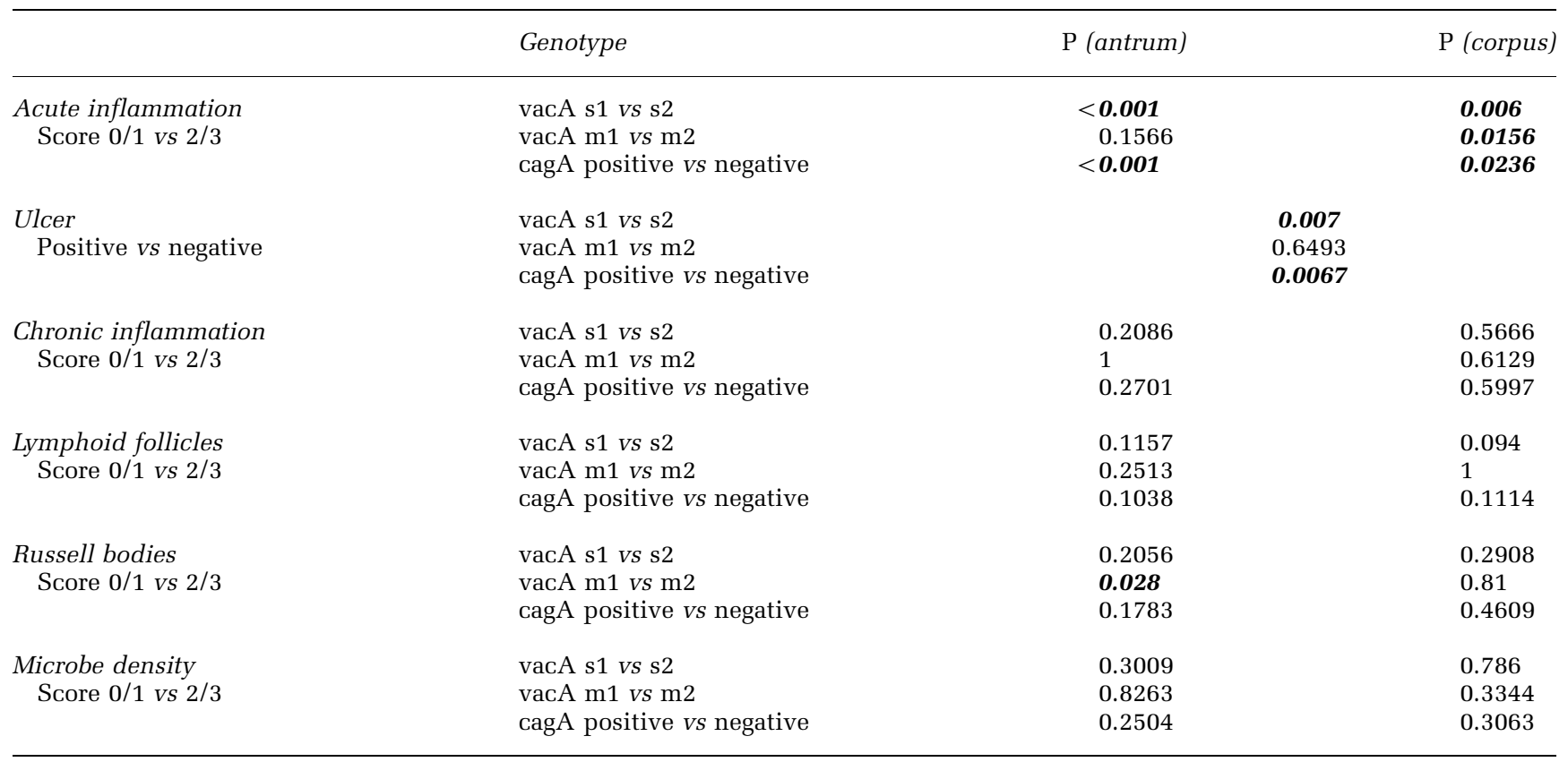

Table 6 Correlation of the parameters IM, vacA s, vacA m and cagA genotype with the patient's age (Wilcoxon rank sum test for IM, vacA $\mathrm{m}$ and cagA, Kruskal-Wallis test for vacA s), bold italic: $P<0.05$

\begin{tabular}{|c|c|c|c|c|c|c|}
\hline & $\mathrm{n}$ & Mean & s.d. & Min & $\operatorname{Max}$ & P-value \\
\hline IM+ & 47 & 54.83 & 14.74 & 25 & 84 & 0.012 \\
\hline IM- & 73 & 47.77 & 13.69 & 22 & 77 & \\
\hline vacA s1 & 86 & 50.01 & 15.01 & 22 & 84 & 0.711 \\
\hline vacA s2 & 26 & 52.85 & 12.58 & 29 & 77 & \\
\hline vacA s1+2 & 8 & 48.63 & 15.19 & 25 & 77 & \\
\hline vacA m1 & 40 & 48.55 & 14.30 & 25 & 84 & 0.239 \\
\hline vacA m2 & 80 & 51.53 & 14.54 & 22 & 83 & \\
\hline cagA+ & 86 & 49.37 & 15.22 & 22 & 84 & 0.194 \\
\hline cagA- & 34 & 53.47 & 12.08 & 29 & 77 & \\
\hline Total & 120 & 50.53 & 14.47 & 22 & 84 & \\
\hline
\end{tabular}

patients carrying a low virulent $H$. pylori strain vacA s2 m2 cagA - was 3 (s2 vs s1, $P>0.05$ ), 3 (m2 vs m1, $P>0.05)$ and 4 (cagA $-v s+, P>0.05$ ) years higher than their counterparts vacA s1 m1 cagA + (Table 6). Finally, a binary logistic regression was calculated, using IM as the binary dependent variable. Age, sex and vacA s allele $\times$ cagA were tested as the independent influence parameters. To this end, we have split the parameter age into three groups (patients with 21-40, 41-60 and 61-84 years old). Forty-nine percent of the patients were men, 51\% were women. The $P$-value for the goodness of fit was 0.05 , explaining $5 \%$ of data by this model.

\section{Discussion}

In recent years, the relationships between histological parameters of gastritis, H. pylori infection, virulence parameters of this microbe and age have started to be investigated. $H$. pylori infection is normally acquired in early childhood. In senescence, the current view claims that (1) prolonged infection with $H$. pylori is the major determinant for development of IM in the stomach; (2) with aging, the inflammation of the antrum burns out (as measured by a decrease of the antrum gastritis sum score); (3) the microbes, the inflammation process and the corpus-antrum border are consecutively shifting (as measured by an increase of the corpus gastritis sum score); and (4) the gastric acid secretion declines. ${ }^{18-25}$ The prevalence of $H$. pylori infection is generally supposed to increase with age. ${ }^{26}$ More recently, it was reported in Japan, that the prevalence of positive rate of serum anti- $H$. pylori-IgG as well as $H$. pylori infection detected histological and by the ${ }^{13} \mathrm{C}$-urea breath test is decreasing in longliving elderly, leading to a concomitant decrease of 
the prevalence of gastric cancer in subjects older than 85 years. ${ }^{27}$

Concerning IM, the authors reported an increase with age in either $H$. pylori-negative or -positive patients. Other authors observed that IM is caused by both the aging process and the $H$. pylori infection. ${ }^{28,29}$ We decided to compare $H$. pyloriinfected patients with IM vs patients without IM, as the presence of IM tags the stomach to be at risk for more severe lesions. Moreover, in routine daily pathology practice, the parameter IM is easily recognized and intra-observer variability is low. ${ }^{30}$ In our study, H. pylori-infected patients with IM are, on the one hand, older at the time point of diagnosis. On the other hand, the presence of IM correlated with more virulent $H$. pylori microbes. Regarding only age and genotype, there was a trend for more virulent microbes to be associated with younger individuals. When combining these parameters in a binary logistic regression, we obtained a $P$-value of 0.05 for the goodness of fit indicating that $5 \%$ of data is explained by the model; therefore additional factors must contribute to the formation of IM.

We observed a tendency for the formation of the incomplete type of IM for the more virulent genotype. The incomplete type IM (type 2) is considered to be more severe than the complete type 1 in terms of potential dysplasia precursor. The even worse type 3 was not found in our study, cf. $^{31}$ To mention, we have evaluated only the antral IM, as IM in corpus biopsies was rare. Further, it has been reported that pan-gastritis in $H$. pylori-infected patients is associated with a higher density of lymphoid aggregates and follicles in the corpus of younger individuals and in the antrum of older individuals with positive family history of gastric cancer. ${ }^{32}$ Lymphoid follicles, as measured in the pyloric gland area of the lesser curvature, are more frequently observed in $H$. pylori-positive stomach biopsies and are positively correlated with the microbial density score. ${ }^{33}$ We did not observe a significant correlation with the intensity of the diffuse chronic inflammation or the formation of lymphoid follicles in either antrum or corpus. In contrast, more virulent microbes, as defined by the vacA $\mathrm{m} 1$ allele, were found to produce a more productive plasmocytic response in the antrum, measured by more frequent and larger Russell bodies. The extensive diffuse stromal infiltration by Russell bodies containing plasma cells, so-called Russell body gastritis, ${ }^{34,35}$ was not observed.

In conclusion, the virulence genotype of the microbe is an important determinant for the severity of acute gastritis and the formation of antral IM. Age is an additional factor for the development of IM. The presence of this histological feature should alert the surgical pathologist to take into consideration a more virulent microbial colonization and a higher patient's age. From a therapeutically point of view, patients with IM tagged stomach may be controlled more carefully and their more virulent strain may be eradicated preferentially.

\section{Acknowledgements}

We thank Professor J Huesler (Institute of Mathematical Statistics and Actuarial Science, University of Bern) for critical reading of the manuscript. The Gastroenterologists P Eichenberger, R Gueller, K Weber and J Meier are acknowledged for providing biopsy material, R Frank and G Frei for excellent technical assistance. Financial support: Institute of Surgical Pathology, University Hospital Zürich, and Institute of Clinical Pathology, Kantonsspital Baden.

\section{Conflict of interest}

The authors have no competing interest.

\section{References}

1 Marshall BJ, Warren JR. Unidentified curved bacilli in the stomach of patients with gastritis and peptic ulceration. Lancet 1984;1:1311-1315.

2 Scholte GH, van Doorn LJ, Cats A, et al. Genotyping of Helicobacter pylori in paraffin-embedded gastric biopsy specimens: relation to histological parameters and effects on therapy. Am J Gastroenterol 2002;97: 1687-1695.

3 Zambon CF, Navaglia F, Basso D, et al. Helicobacter pylori babA2, cagA, and s1 vacA genes work synergistically in causing intestinal metaplasia. J Clin Pathol 2003;56:287-291.

4 van Doorn LJ, Figueiredo C, Rossau R, et al. Typing of Helicobacter pylori vacA gene and detection of cagA gene by PCR and reverse hybridization. J Clin Microbiol 1998;36:1271-1276.

5 Hocker M, Hohenberger P. Helicobacter pylori virulence factors-one part of a big picture. Lancet 2003;362:1231-1233.

6 Selbach M, Moese S, Meyer TF, et al. Functional analysis of the Helicobacter pylori cag pathogenicity island reveals both VirD4-CagA-dependent and VirD4CagA-independent mechanisms. Infect Immun 2002;70:665-671.

7 Censini S, Lange C, Xiang Z, et al. cag, a pathogenicity island of Helicobacter pylori, encodes type I-specific and disease-associated virulence factors. Proc Natl Acad Sci USA 1996;93:14648-14653.

8 Amieva MR, Vogelmann R, Covacci A, et al. Disruption of the epithelial apical-junctional complex by Helicobacter pylori CagA. Science 2003;300:1430-1434.

9 Segal ED, Lange C, Covacci A, et al. Induction of host signal transduction pathways by Helicobacter pylori. Proc Natl Acad Sci USA 1997;94:7595-7599.

10 Cover TL, Blaser MJ. Purification and characterization of the vacuolating toxin from Helicobacter pylori. J Biol Chem 1992;267:10570-10575.

11 McClain MS, Iwamoto H, Cao P, et al. Essential role of a GXXXG motif for membrane channel formation by Helicobacter pylori vacuolating toxin. J Biol Chem 2003;278:12101-12108. 
12 Atherton JC, Cao P, Peek Jr RM, et al. Mosaicism in vacuolating cytotoxin alleles of Helicobacter pylori. Association of specific vacA types with cytotoxin production and peptic ulceration. J Biol Chem 1995; 270:17771-17777.

13 Dixon MF, Genta RM, Yardley JH, et al. Classification and grading of gastritis. The updated Sydney System. International Workshop on the Histopathology of Gastritis, Houston 1994. Am J Surg Pathol 1996;20: 1161-1181.

14 van Doorn LJ, Glupczynski Y, Kusters JG, et al. Accurate prediction of macrolide resistance in Helicobacter pylori by a PCR line probe assay for detection of mutations in the 23S rRNA gene: multicenter validation study. Antimicrob Agents Chemother 2001;45: 1500-1504.

15 Maeda S, Yoshida H, Ogura K, et al. Helicobacter pylori specific nested PCR assay for the detection of 23S rRNA mutation associated with clarithromycin resistance. Gut 1998;43:317-321.

16 Rice JA. Mathematical Statistics and Data Analysis, 3rd edn. Thompson: Belmont, 2007.

17 Fisher LD, van Belle G. Biostatistics: A Methodology for the Health Sciences. Wiley: New York, 1993.

18 Haruma K, Kamada T, Kawaguchi H, et al. Effect of age and Helicobacter pylori infection on gastric acid secretion. J Gastroenterol Hepatol 2000;15:277-283.

19 Asaka M, Kato M, Kudo M, et al. Atrophic changes of gastric mucosa are caused by Helicobacter pylori infection rather than aging: studies in asymptomatic Japanese adults. Helicobacter 1996;1:52-56.

20 Asaka M, Sugiyama T, Nobuta A, et al. Atrophic gastritis and intestinal metaplasia in Japan: results of a large multicenter study. Helicobacter 2001;6: 294-299.

21 Hackelsberger A, Gunther T, Schultze V, et al. Role of aging in the expression of Helicobacter pylori gastritis in the antrum, corpus, and cardia. Scand J Gastroenterol 1999;34:138-143.

22 Satoh K, Kimura K, Taniguchi Y, et al. Distribution of inflammation and atrophy in the stomach of Helicobacter pylori-positive and -negative patients with chronic gastritis. Am J Gastroenterol 1996;91:963-969.

23 Kuipers EJ, Uyterlinde AM, Pena AS, et al. Long-term sequelae of Helicobacter pylori gastritis. Lancet 1995;345:1525-1528.
24 Pilotto A, Salles N. Helicobacter pylori infection in geriatrics. Helicobacter 2002;7(Suppl 1):56-62.

25 Faller G, Kirchner T. Immunological and morphogenic basis of gastric mucosa atrophy and metaplasia. Virchows Arch 2005;446:1-9.

26 Iijima K, Ohara S, Koike T, et al. Gastric acid secretion of normal Japanese subjects in relation to Helicobacter pylori infection, aging, and gender. Scand J Gastroenterol 2004;39:709-716.

27 Kawade M, Joh T, Oshima T, et al. Prevalence of gastric cancer decreases with age in long-living elderly in Japan, possibly due to changes in Helicobacter pylori infection status. J Gastroenterol Hepatol 2005;20: 1333-1337.

28 Ohkuma K, Okada M, Murayama H, et al. Association of Helicobacter pylori infection with atrophic gastritis and intestinal metaplasia. J Gastroenterol Hepatol 2000;15:1105-1112.

29 Tsukui T, Kashiwagi R, Sakane M, et al. Aging increases, and duodenal ulcer reduces the risk for intestinal metaplasia of the gastric corpus in Japanese patients with dyspepsia. J Gastroenterol Hepatol 2001;16:15-21.

30 Ruiz B, Garay J, Correa P, et al. Morphometric evaluation of gastric antral atrophy: improvement after cure of Helicobacter pylori infection. Am J Gastroenterol 2001;96:3281-3287.

31 Suriani R, Venturini I, Taraglio S, et al. Type III intestinal metaplasia, Helicobacter pylori infection and gastric carcinoma risk index in an Italian series of 1750 patients. Hepatogastroenterology 2005;52:285-288.

32 Sepulveda A, Peterson LE, Shelton J, et al. Histological patterns of gastritis in $H$. pylori-infected individuals with a family history of gastric cancer. Am J Gastroenterol 2002;97:1365-1370.

33 Ma ZQ, Tanizawa T, Nihei Z, et al. Follicular gastritis associated with Helicobacter pylori. J Med Dent Sci 2000;47:39-47.

34 Ensari A, Savas B, Okcu Heper A, et al. An unusual presentation of Helicobacter pylori infection: so-called 'Russell body gastritis'. Virchows Arch 2005;446: 463-466.

35 Tazawa K, Tsutsumi Y. Localized accumulation of Russell body-containing plasma cells in gastric mucosa with Helicobacter pylori infection: 'Russell body gastritis'. Pathol Int 1998;48:242-244. 